\title{
Introduction to the Special Issue on Mental Illness and Health in the Workplace
}

\author{
Melissa A. Parris
}

Published online: 5 November 2013

(C) Springer Science+Business Media New York 2013

This special issue of Employee Responsibilities and Rights Journal is dedicated to examining issues of mental illness and health in the workplace. While debate exists as to whether the prevalence of mental illness is increasing in the global population or it is the level of diagnosis that is higher than in the past (Moffitt et al. 2010; Baumeister et al. 2012), there are a growing number of individuals identified as living with one or more mental illnesses. Despite this increase, issues related to mental health still remain largely "hidden" in the workplace. The stigma attached to mental health conditions would appear to be a key contributor to individuals' concerns in being forthcoming about their condition (Corrigan et al. 2012). There have been public policy attempts in many countries at reducing such stigma, such as those aligned with World Mental Health Day (World Federation for Mental Health 2013). Nevertheless, negative attitudes and stereotypes of various mental illnesses persist, including amongst organizational managers (Martin 2010). In line with the Journal's aims, the articles that follow provide analysis and recommendations from the perspective of both employees and employers.

In our opening article, Employee Mental Illness: Managing the Hidden Epidemic, De Lorenzo begins with a detailed review of research on the prevalence of mental illness in the general population - and the potential implications from both disclosure and non-disclosure in the workplace. De Lorenzo takes the stance that, while we await further shifts in societal perceptions of mental illness, organizations still need to be able to address potentially exacerbating factors and other outcomes in the workplace regardless of the level of "visibility" among their employees. Accordingly, she concludes by outlining a proposal for policies that can assist organizational leaders in the sensitive workplace management of hidden mental illness.

Pryce continues the focus on outcomes for 'all parties involved in employment relationships' with her article, An Evaluation of 'Work' for People with a Severe Persistent Mental Illness. The arguments Pryce eloquently develops align with the themes of other critical researchers in evaluating the "meaning of work" (e.g. Cartwright and Holmes 2006; Rosso et al. 2010). Within the particular context of people with a severe persistent mental illness, she argues that opportunities for constructive outcomes for both employees and employers can be constrained through the continued use of a narrow definition of employment.

M. A. Parris $(\bowtie)$

School of Management and Marketing, Deakin University, Burwood, Victoria, Australia

e-mail: melissa.parris@deakin.edu.au 
In Facing Adversity: Authentic Stories of Living and Working with Panic Attacks, Perrone, Vickers and Wilkes provide an insightful contribution to the special issue through their examination of employee experiences with one particular mental health concern, that of panic attacks. The authors present vivid stories from their respondents that again highlight the hidden and often "unknown" nature of mental illness, and how symptoms may even be exacerbated by the stigma attached to this condition.

Fairclough, Robinson, Nichols and Cousley also focus on a particular aspect of mental illness in their article, In Sickness and in Health: Implications for Employers when Bipolar Disorders are Protected Disabilities. Situated within the context of US employment law, Fairclough and colleagues provide a well-grounded contribution to discussion on mental illness and health in the workplace, particularly through considering employer responsibilities for all employees in an organization.

Finally, our Perspectives Editor, Victor Devinatz, provides an introduction (that I won't preempt here) to How Do Social Networks Influence the Employment Prospects of People with Disabilities?. This issue's Perspectives article provides a strong complement to the articles in the special issue through its discussion of support for individuals with disabilities, whether physical or mental health conditions.

I would like to take this opportunity to express my thanks to our hard-working Editorial Board members for their constructive feedback on the special issue submissions, and also our other invited reviewers. Importantly, I thank the authors represented in this special issue for their theoretically grounded and engaging contributions. I trust the articles presented here will help provide insight into the various experiences of individuals who constitute a significant percentage of the employee (and prospective employee) population.

\section{References}

Baumeister, A. A., Hawkins, M. F., Lee Pow, J., \& Cohen, A. S. (2012). Prevalence and incidence of severe mental illness in the United States: an historical overview. Harvard Review of Psychiatry, 20(5), 247-258.

Cartwright, S., \& Holmes, N. (2006). The meaning of work: the challenge of regaining employee engagement and reducing cynicism. Human Resource Management Review, 16(2), 199-208.

Corrigan, P. W., Powell, K. J., \& Rüsch, N. (2012). How does stigma affect work in people with serious mental illnesses? Psychiatric Rehabilitation Journal, 35(5), 381-384.

Martin, A. (2010). Individual and contextual correlates of managers' attitudes towards depressed employees. Human Resource Management, 49(4), 647-668.

Moffitt, T. E., Caspi, A., Taylor, A., Kokaua, J., Milne, B. J., Polanczyk, G., \& Poulton, R. (2010). How common are mental disorders? Evidence that lifetime prevalence rates are doubled by prospective versus retrospective ascertainment. Psychological Medicine, 40(6), 899-909.

Rosso, B. D., Dekas, K. H., \& Wrzesniewski, A. (2010). On the meaning of work: a theoretical integration and review. Research in Organizational Behavior, 30, 91-127.

World Federation for Mental Health (2013). World mental health day. http://www.wfmh.org/ 00WorldMentalHealthDay.htm. Accessed 10 October 2013. 